\title{
Getting Less Cynical about Virtue
}

\author{
Joshua May \\ Published in Moral Psychology, Vol. 5: Virtue \& Character, \\ W. Sinnott-Armstrong \& C. Miller (eds.), MIT Press (2017), pp. 45-52. \\ [This is the penultimate draft; for citations see final published version.]
}

\begin{abstract}
This is a commentary on a paper by the social psychologist C. Daniel Batson. I too think virtue is rare, but not so rare as Batson seems to think, despite his ingenious experiments on "moral hypocrisy."
\end{abstract}

As usual, Dan Batson provides an experimentally rigorous, yet philosophically sophisticated, account of moral motivation - a model for exemplary work in moral psychology. I'll attempt to summarize some of the main ideas in his illuminating essay but focus on raising some worries, despite much agreement otherwise. I too am cynical about character: virtue, like moral knowledge, is precarious. However, I will try to motivate the idea that we are more virtuous and morally motivated than Batson suggests.

Batson gets cynical about character in two different ways and for two different reasons. First, character, as a psychological posit, isn't useful. This is perhaps an unsurprising conclusion from a psychologist who many view as a father of situationism. But Batson's reason for skepticism about character traits has little to do with the surprising role situational factors play in behavior. After all, we're rather consistently egoistic across a wide range of situations, as some of Batson's studies suggest (see also the discussion in Kleingeld 2015). Rather, we needn't appeal to character to explain moral and immoral behavior, Batson says, because we achieve a deeper understanding of behavior by looking to motives and values (which, by the way, can vary easily with the situation). In particular, we should identify ultimate (or intrinsic) goals, which are pursued for their own sake, not as a means to something else.

Second, Batson is cynical about character in the sense that good character is rare. By good character - at least good moral character - he seems to mean moral integrity: motivation to uphold moral principles for their own sake. We're often ultimately driven by self-interest (egoism) instead of a concern to be moral. Now this conclusion is perhaps surprising from such an ardent defender of the existence of altruism (Batson 2011). However, while we can be ultimately motivated by moral principles and by a concern for others, Batson believes egoism is more common. The latest theme in his research suggests that, even when it comes to moral behavior, we are often ultimately motivated to appear moral while avoiding the cost of being moral if possible (the motive of moral hypocrisy). In other words, Batson believes that good character is rare because moral integrity is rare, while moral hypocrisy and other forms of egoistic motivation are prevalent.

I'll focus only on Batson's second form of cynicism and aim to raise two worries for it. First, I'll suggest the experiments on moral hypocrisy and other data in psychology may provide evidence for moral integrity. Second, while moral hypocrisy 
no doubt exists, its scope in our lives may be limited. But first let's consider whether virtue or good character does require moral integrity.

\section{Virtue without Moral Integrity?}

Batson connects virtue with moral motivation, contrasting good moral character with self-interested motivation in particular, much in the spirit of Kant. The idea is intuitive enough. If we discover that, say, Raoul Wallenberg rescued so many Jews from the horrors of the Holocaust ultimately just for fame, our reverence for his deeds would surely diminish. But do we require of such heroes that they be ultimately motivated by moral principles?

What Batson calls "moral integrity" (or "principlism" in Batson 2011) includes the ultimate goal of upholding specific moral principles, such as be fair. But it also appears to include what philosophers have called the "motive of duty" - the ultimate motivation to do whatever is right, as such. Suppose I'm deliberating about whether to lie to my mother to spare her feelings or to be honest. I value honesty, but I opt to lie because I conclude being kind in this situation is the right thing to do. Here, let's suppose, I'm ultimately motivated to do whatever is right. As Kant says, such actions are not just in conformity with duty but done from duty.

Some ethicists believe this is too demanding, as it involves an obsession with abstract morality, a fetishizing that amounts to a vice. Imagine, for example, that Michael visits a friend in the hospital ultimately because he just wants to do the right thing. Michael exhibits moral integrity, but wouldn't it be more appropriate - more virtuous - to just be motivated ultimately by a concern for his friend's well-being (Stocker 1976)? Moral integrity might alienate us in this way from the personal attachments that often provide us with moral obligations in the first place.

These are disputed issues among philosophers. My own view is that anything like the motive of duty is difficult to count as a vice given that we often happily and unabashedly describe our own actions as done simply "because I believe it's the right thing to do" (May 2013). Perhaps moral integrity can more often conflict with certain virtues or only in certain cases, such as helping close friends in need (Aboodi 2015). But it's less often problematic when doing right by strangers (as in Batson's experiments) or in altering one's behavior in light of changes in moral belief (Carbonell 2013). Consider again the white lie to my mother. If I initially believe it would be wrong to lie to her, but then change my mind, it's fitting to be motivated to do whatever is right, as such. Moral integrity is needed to appropriately structure such deliberations.

So I prefer a pluralistic approach. Moral integrity is sometimes a component of good moral character, but not always. In Batson's defense, that is presumably all he needs for cynicism. If moral integrity is rare while egoism is common, then virtue is at least on thin ice.

\section{The Prevalence of Moral Integrity}

How rare is moral integrity? Batson's main evidence is a series of brilliant experiments suggesting that at least some moral behavior is often motivated by self-interest. Participants are asked to assign one of two tasks to themselves and another person. One 
is positive or rewarding while the other task is boring or negative. Left to their own devices, people tend to allocate the positive task to themselves, and the negative one to the other person. When offered a fair procedure (e.g. flipping a coin), about half use it, but somehow such participants overwhelmingly award themselves the positive task. It turns out that people secretly manipulate or ignore the fair procedure to benefit themselves. Many thus seem motivated by moral hypocrisy: to appear moral while avoiding the costs of actually being moral when there's sufficient wiggle room.

As Batson notes, this fits with a growing literature that suggests we're highly prone to cheat if it yields greater benefits and we think we can fudge the results to our own satisfaction (e.g. Ariely 2012). Even when we can just say "To hell with what's right," we instead more often say (or think) "I deserve the reward" or "Anyone else would do the same." Frequently we're willing to violate our own scruples - from morality to prudence - if we can deviously portray it as acceptable. As Groucho Marx once quipped: "Those are my principles, and if you don't like them, well, I have others."

Much as the road to hell is paved with good intentions, the route to temptation is paved with rationalization. Sometimes we concoct poor reasons for a self-serving choice already made (post hoc), but we take preemptive measures too by rationalizing a tempting choice before its made (ante hoc). It may seem that we succumb to temptation by the brute pull of passion or selfish desire. Rationalization, however, is a cognitive affair that involves changes in moral judgment or, more broadly, normative or evaluative judgment (Holton 2009). Humans often succumb by persuading themselves that what they're about to do is justifiable (compare Watson 1999). If this is right, then quite often we might be motivated by moral integrity - an ultimate concern to act in ways we can justify in terms of moral principles or ideals we accept (compare Sie 2015).

Consider the hypocrisy experiments in more detail. Participants will often fudge their use of a fair allocation procedure in order to ensure they assign the rewarding task to themselves. However, participants don't exploit the wiggle room in order to avoid detection by others. They apparently cheat only by engaging in self-deception. The evidence suggests that people are not deceiving themselves by misremembering how the benefit was to be distributed (e.g. "Heads meant I get the good task, right?"). Rather, they seem to be avoiding an explicit comparison of the self-interested action to their moral standards. Batson believes the best explanation of this is an ultimate motivation to merely appear moral. But it may be too quick to rule out motivation by moral principles (integrity).

It's significant that participants are sensitive to whether their actions can be morally justified, despite no perceived risk of being caught. In all of the experiments, participants are led to believe that no one will know how they made their choice. So why do they fiddle with the flip? Why not just bypass the coin flip altogether? And why does fairness increase when one is more liable to compare one's behavior to moral standards (e.g. in the presence of a mirror)?

A plausible explanation posits an ultimate motive to conform to one's scruples (moral integrity). After all, participants who did act unfairly later rated their actions as more morally acceptable, provided they were able to justify it to themselves (e.g. by flipping the coin but fudging the results). This should be expected since the process of rationalization only makes sense in creatures who are ultimately concerned to uphold their principles, even in private. An ultimate goal of merely appearing moral to others is 
undoubtedly egoistic, but ultimately aiming to appear moral to oneself involves moral integrity, for one must then represent the act as moral in order to achieve one's goal. Accounting for participants' unfairness only by appeal to egoism struggles to explain why they act unfairly by justifying it to themselves (ante hoc rationalization). After all, being motivated to uphold a moral principle doesn't serve self-interest unless one antecedently cares about being moral.

Of course, doing what's right might seem to promote one's interests if others will witness it and dole out praise or financial rewards, but that isn't the case here. It may seem that morality serves self-interest if one would feel bad about acting immorally. But why would being moral yield positive feelings (or avoid negative ones) in the absence of an intrinsic concern for morality or justifiability? Feeling bad about violating one's own moral scruples seems to presuppose a concern to be moral. Absent such a concern, feeling guilt is inappropriate and would call for a special explanation (compare Slote 2013 on guilt being incompatible with egoism). Merely seeking to avoiding punishment or censure calls for fear, not guilt. Thus, it's plausible that participants' motivation to be moral is ultimate, not instrumental to an egoistic goal.

Self-interest is surely playing a role for most participants, since they are rationalizing the selfish choice. Perhaps the self-interested motive is even ultimate. The best explanation is likely mixed, positing multiple ultimate goals, particularly egoism and moral integrity (compare Ariely 2012), perhaps also altruism. Positing multiple ultimate goals, however, is compatible with my main claim, which is just that we haven't ruled out moral integrity in the hypocrisy experiments.

Of course, it doesn't seem particularly virtuous to uphold principles corrupted by (ante hoc) rationalization. However, I am merely challenging the claim that moral integrity is infrequent, since Batson's assumption is that virtue requires it. It's a separate question whether the prevalence of rationalization threatens the prominence of virtue. My own view is that, to a certain extent, it does. Whether the situation is truly tragic, though, depends partly on how pervasive egoistic motives (like moral hypocrisy) arean issue to which we should now turn.

\section{The Limits of Moral Hypocrisy}

Perhaps a cynic could claim victory, even while accepting that moral integrity exists, provided that moral hypocrisy is more frequent. There are at least three reasons to be doubtful of this strategy.

First, rationalization appears to be rather prevalent in a variety of contexts. Motivated reasoning induces wishful thinking of all sorts (see Kunda 1990), and again there is some evidence that this often works through changes in normative or evaluative judgment (Holton 2009). For example, one study found that children as young as 8 appear to devalue a treat they initially ranked as worth waiting for, once they're tempted to instead simply take the lesser treat sitting right in front of them (Karniol \& Miller 1983). By devaluing what was previously thought more valuable, one can rationalize a different option. Like Aesop's fox, we sometimes judge the grapes to be sour once we realize they're out of reach. If, as I've suggested, rationalization when deliberating about moral matters implicates moral integrity, then such a non-egoistic motive is prevalent. 
Second, as Batson's earlier research suggests, we also sometimes have an ultimate concern for the well-being of others. In particular, when we empathize with others in need, we are more likely to be ultimately motivated by genuine altruism. In fact, I have defended Batson's empathy-altruism hypothesis against various attacks (e.g. May 2011). Thus, I believe we have strong evidence-from common experience to rigorous experiments - suggesting that we can at least sometimes have other morally laudable motives that rise above egoism. Given the pluralistic approach to virtue outlined earlier, we may include altruism as part of a virtuous character (compare Miller 2013).

The third reason to be doubtful of the scope of egoistic motives like moral hypocrisy is that we have some evidence that it isn't so rampant. After all, Batson's key experiments purporting to demonstrate its existence might not have ruled out my rationalization hypothesis and at best demonstrate mixed motives of integrity and hypocrisy. More importantly, even if we have strong evidence of moral hypocrisy, there is some reason to think that egoistic motives driven by rationalization are constrained by an ultimate desire to be moral (moral integrity).

Consider the extensive studies now done on cheating and honesty, primarily conducted by Dan Ariely and his collaborators (see Ariely 2012). Such experiments have consistently shown, as Ariely says, that most people cheat a little but not a lot (compare Miller 2016). Many of the studies involve presenting participants with an opportunity to lie with impunity about the number of problems they solved, thus increasing the cash they can pocket at the end of the experiment. For example, in one study, those who had an opportunity to cheat claimed on average to solve only 2 more math problems ( 6 out of 20 total) than those without an opportunity to be dishonest (4 out of 20). Importantly, the average difference wasn't due to a select minority of amoral liars who claimed to solve most of the problems but rather to "lots of people who cheated by just a little bit" (2012: 23). Such results in this line of research are the norm, even when the payout per problem solved is substantially increased. Moreover, the best explanation again appeals to rationalization: we tend to cheat only a little because that's the amount we can justify to ourselves (or to others if they happen to find out). Increasing the "fudge factor," as Ariely puts it, increases cheating because it allows one to rationalize bending the moral rules.

So do we ultimately lack virtue or good character? Is there something "wrong with morality," as Batson (2016) has put it? Certainly to some degree. We may categorically lack good character but only if the bar for virtue is rather high. Perhaps even then many of us are not vicious but simply have "mixed" character traits (Miller 2013). Either way, I doubt the situation is quite as dire as Batson lets on. Like our propensities to cheat, we should be a little bit cynical about good character, but not a lot.

Acknowledgements: For feedback, I'm grateful to Karl Aquino, Dan Batson, George Graham, Christian Miller, and Walter Sinnott-Armstrong. 


\section{References}

Aboodi, Ron (2015). "The Wrong Time to Aim at What's Right: When is De Dicto Moral Motivation Less Virtuous?" Proceedings of the Aristotelian Society 115 (3pt3):307-314. Ariely, Dan (2012). The Honest Truth About Dishonesty. HarperCollins.

Batson, C. D. (2011). Altruism in Humans. Oxford University Press.

Batson, C. D. (2016). What's Wrong with Morality? Oxford University Press.

Carbonell, Vanessa (2013). "De Dicto Desires and Morality as Fetish." Philosophical Studies 163(2):459-477.

Holton, Richard (2009). Willing, Wanting, Waiting. Oxford: Clarendon Press.

Karniol, Rachel \& Miller, Dale T. (1983). "Why Not Wait? A Cognitive Model of Self-Imposed Delay Termination." Journal of Personality and Social Psychology 43 (4): 935-942.

Kleingeld, Pauline (2015). "Consistent Egoists and Situation Managers." Philosophical Explorations 18(3): 344-361.

Kunda, Ziva (1990). "The Case for Motivated Reasoning." Psychological Bulletin 108(3):48098.

May, Joshua (2011). "Egoism, Empathy, and Self-Other Merging" Southern Journal of Philosophy 49(S1): 25-39, Spindel Supplement: Empathy \& Ethics, R. Debes (ed.).

May, Joshua (2013). "Because I Believe It's the Right Thing to Do." Ethical Theory \& Moral Practice 16(4): 791-808.

Miller, Christian (2013). Moral Character: An Empirical Theory. Oxford University Press.

Miller, Christian (2016). "Honesty." In Moral Psychology Vol. 5: Virtue \& Happiness, W. Sinnott-Armstrong \& C. Miller (eds.), MIT Press.

Sie, Maureen (2015). "Moral Hypocrisy and Acting for Reasons: How Moralizing Can Invite Self-Deception." Ethical Theory and Moral Practice 18(2): 223-235.

Slote, Michael (2013). "Egoism and Emotion." Philosophia 41(2):313-335.

Stocker, Michael (1976). "The Schizophrenia of Modern Ethical Theories." The Journal of Philosophy 73(14):453-466.

Watson, Gary (1999). "Disordered Appetites: Addiction, Compulsion and Dependence." Addiction: Entries and Exits, Jon Elster (ed.). New York: Russell Sage. 